\title{
Visceral obesity enhances inflammatory response after laparoscopic colorectal resection
}

\author{
Cristian Conti ${ }^{1}$, Corrado Pedrazzani ${ }^{1}$, Giulia Turri ${ }^{1}$, Gabriele Gecchele ${ }^{1}$, Alessandro \\ Valdegamberi $^{1}$, Andrea Ruzzenente ${ }^{1}$, Giulia Zamboni ${ }^{1}$, Giuseppe Lippi ${ }^{1}$, and Alfredo \\ Guglielmi ${ }^{1}$ \\ ${ }^{1}$ University of Verona
}

July 8, 2021

\begin{abstract}
Aims: C-reactive protein (CRP) is commonly used for monitoring Surgical Stress Response (SSR) and detecting post-operative infectious complications. However, high CRP values can be associated to patient-related factors independently from complications. The aim of this study was to assess the relationship between visceral obesity (VO) and SSR after laparoscopic colorectal resection. Methods: Visceral adipose tissue (VAT) area was measured at CT images for 357 patients who underwent elective laparoscopic colorectal resection at our institution. Post-operative outcomes and CRP values were compared between VO and non-VO groups, defined according to VAT cut-offs. Univariate and multivariate analyses were conducted for factors affecting SSR. ROC curves were constructed to assess the most appropriate CRP values for identifying infectious complications in the VO and non-VO populations. Results: In the final cohort, $62.2 \%$ of patients were classified as VO. No differences were seen in post-operative outcomes and infectious complications. VO was associated with higher CRP values on post-operative day (POD)1, POD2, POD3, and POD5, considering both the overall cohort and patients without infectious complications. A positive correlation was found between VAT and CRP values on all PODs, and VO independently predicted increased CRP on POD1-3 in patients without infectious complications but not in those who developed complications. ROC curves analysis for POD3 CRP showed comparable accuracy for detection of infectious complications in both groups, though the optimal cut-off value was higher in VO group (154 vs. $136 \mathrm{mg} / \mathrm{dl}$ ). Conclusions: Although VO is not associated to increased complications after laparoscopic colorectal resection, it independently predicts increased SSR risk. To achieve accurate identification of infectious complications, different cut-off values of POD3 CRP shall be used in VO and non-VO patients.
\end{abstract}

Title:Visceral obesity enhances inflammatory response after laparoscopic colorectal resection

Running title : Visceral obesity enhances inflammatory response

Authors: Conti Cristian MD, Pedrazzani Corrado Prof, Turri Giulia MD, Gecchele Gabriele MD, Valdegamberi Alessandro MD, Ruzzenente Andrea Prof, Zamboni Giulia A. Prof, Lippi Giuseppe Prof, Guglielmi Alfredo Prof.

Cristian Conti, Corrado Pedrazzani, Giulia Turri, Gabriele Gecchele, Alessandro Valdegamberi, Ruzzenente Andrea, Alfredo Guglielmi : Division of General and Hepatobiliary Surgery, Department of Surgical Sciences, Dentistry, Gynecology and Pediatrics, University of Verona, Verona, Italy

Giulia A. Zamboni : Section of Radiology, Department of Diagnostic and Public Health, Section of Radiology, University of Verona, Verona, Italy

Giuseppe Lippi : Section of Clinical Biochemistry, Department of Neurological, Biomedical and Movement Sciences, of , . 
Corresponding author : Prof. Corrado Pedrazzani, Division of General and Hepatobiliary Surgery, "G.B. Rossi", Piazzale "L. Scuro" 10, 37134 . Tel: ++39 (0)45 8126719.

E-mail:corrado.pedrazzani@univr.it.

Conflict of interest : Conti C., Pedrazzani C., Turri G., Gecchele G., Valdegamberi A., Ruzzenente A., Zamboni G.A., Lippi G., Guglielmi A. have no conflict of interests or funding to declare

\section{ABSTRACT}

Aims : C-reactive protein (CRP) is commonly used for monitoring Surgical Stress Response (SSR) and detecting post-operative infectious complications. However, high CRP values can be associated to patientrelated factors independently from complications. The aim of this study was to assess the relationship between visceral obesity (VO) and SSR after laparoscopic colorectal resection.

Methods : Visceral adipose tissue (VAT) area was measured at CT images for 357 patients who underwent elective laparoscopic colorectal resection at our institution. Post-operative outcomes and CRP values were compared between VO and non-VO groups, defined according to VAT cut-offs. Univariate and multivariate analyses were conducted for factors affecting SSR. ROC curves were constructed to assess the most appropriate CRP values for identifying infectious complications in the VO and non-VO populations.

Results : In the final cohort, $62.2 \%$ of patients were classified as VO. No differences were seen in postoperative outcomes and infectious complications. VO was associated with higher CRP values on postoperative day (POD)1, POD2, POD3, and POD5, considering both the overall cohort and patients without infectious complications. A positive correlation was found between VAT and CRP values on all PODs, and VO independently predicted increased CRP on POD1-3 in patients without infectious complications but not in those who developed complications. ROC curves analysis for POD3 CRP showed comparable accuracy for detection of infectious complications in both groups, though the optimal cut-off value was higher in VO group (154 vs. $136 \mathrm{mg} / \mathrm{dl})$.

Conclusions : Although VO is not associated to increased complications after laparoscopic colorectal resection, it independently predicts increased SSR risk. To achieve accurate identification of infectious complications, different cut-off values of POD3 CRP shall be used in VO and non-VO patients.

\section{KEY WORDS}

visceral obesity, C-reactive protein, inflammation, surgical stress response, laparoscopy

\section{What's known?}

The degree of post-operative inflammation or Surgical Stress Response (SSR) can be assessed in clinical practice through bioumoral markers such as C-reactive protein (CRP). In colorectal surgery several factors affect CRP levels such as surgical approach, extent of surgery and occurrence of post-operative complications. Among patient-related factors low skeletal muscle mass is a well-known risk factor for increased SSR after surgery.

\section{what's new?}

This is the first paper which assessed the role of visceral adipose tissue (VAT) on CRP levels and SSR. After laparoscopic colorectal resection visceral obese patients present higher SSR compared to normal patients, independently from post-operative complications. When monitoring the post-operative course through CRP levels, VAT should be considered as a risk factors for non-clinically significant higher values.

\section{Introduction}

Hospitalization and surgical procedures affect normal homeostasis and trigger metabolic stress response. This process is commonly called Systemic Inflammatory Response or Surgical Stress Response (SSR), and involves both immune and neuro-endocrine systems ${ }^{1}$. 
Several approaches have been proposed for assaying SSR in clinical practice, with C-reactive protein (CRP) measurement remaining the most used and affordable strategy. In colorectal surgery several studies confirmed the usefulness of CRP for safe early discharge, aiming at early detection of adverse events ${ }^{2}$. Conversely, several procedure- and patient-related factors could influence SSR, so that specific subgroups of patients may need the estimation and application of specific cut-off values. Among these factors, surgical approach and nutritional status have been recently found to be associated with SSR ${ }^{3-5}$. In particular, low skeletal muscle mass has been associated with increased SSR ${ }^{4}$, whilst little is known on the post-operative pro-inflammatory role of visceral obesity (VO) and its possible clinical implications.

In this study, we assessed the relationship between visceral adipose tissue (VAT) area measured at CT scan and SSR defined according to peri-operative CRP levels. We assumed that VO, defined as VAT excess, could intensify SSR following laparoscopic colorectal surgery, thus requiring specific cut-off values for detecting post-operative infectious complications in VO patients.

\section{Patients and methods}

Patients and study design

From January 2012 to February 2020, four-hundred seventy-six patients underwent elective laparoscopic colorectal resection for benign or malignant disease at the Division of General and Hepatobiliary Surgery, University of Verona Hospital Trust. Exclusion criteria were inflammatory bowel disease $(\mathrm{n}=21)$, familial adenomatous polyposis $(\mathrm{n}=6)$, and mortality within post-operative day (POD) $5(\mathrm{n}=2)$. All patients with missing data or pre-operative CT imaging in our Picture Archiving and Communication System (PACS) were also excluded from analysis $(\mathrm{n}=90)$.

This study was approved by the Ethics Committee of the University Hospital of Verona, Italy (reference number "58642 - CRINF-1560CESC"). All patients provided written informed consent.

Clinical and demographic data

Clinic and pathological data collected included age, sex, and Charlson's comorbidity index (CCI). Patient height, weight, and body mass index (BMI) were recorded from pre-operative assessment. All tumors were confirmed histologically and staged according to the $8^{\text {th }}$ Edition of the American Joint Committee on Cancer (AJCC) TNM Classification. Intraoperative variables were tumor location, type of resection, duration of surgical procedure, blood loss, and need for conversion. ERAS protocol enrollment was registered and all patients followed the previously described pathway ${ }^{6}$.

Post-operative complications were graded according to the Clavien-Dindo Classification and divided into minor (grade I-II) and major grade (grade III-V). When several adverse events occurred in the same patient, the highest grade was adopted. Primary outcome was the rate of infectious complications, which included anastomotic leak, pneumonia and surgical site infections ${ }^{7,8}$. Post-operative length of stay (LOS), 30-day readmission, and reoperation rates were registered together with post-operative mortality.

Laboratory tests

Pre-operative systemic inflammatory condition was assessed through serum CRP within 3 weeks before surgery (Pre-Op CRP). Serum CRP levels in the post-operative period were routinely measured on POD1-3 and on POD4-5, based on clinical indication. The concentration of CRP was measured using a validated immunoturbidimetric assay on a Roche Cobas 8000 (Roche Diagnostics, Basel, Switzerland). The analytical characteristics of this method are as follows: limit of detection, $0.3 \mathrm{mg} / \mathrm{L}$; linearity, $0.3-350 \mathrm{mg} / \mathrm{L}$; intra-assay imprecision, $1.2 \%$ to $3.6 \%$; upper limit of the normal reference range: $<5 \mathrm{mg} / \mathrm{L}$

Body composition analysis

Computed tomography $(\mathrm{CT})$ images were retrieved from digital PACS and analyzed using ImageJ software (ImageJ; The National Institutes of Health, Washington, MD, USA; version 1.47) as previously described ${ }^{9}$. Briefly, VAT area $\left(\mathrm{cm}^{2}\right)$ was measured on a single axial CT image at the third lumbar vertebra (L3) using 
Hounsfield unit (HU) thresholds of -190 to -30 , in line with accepted methodology ${ }^{10,11}$. This parameter is highly correlated with total body adipose tissue ${ }^{12}$.Images analysis was performed by a single researcher specifically trained for the task. VO was defined using sex-specific VAT cut-off values ${ }^{11,13}$ as follows: VO group with VAT $>163.8 \mathrm{~cm}^{2}$ in males and VAT $>80.1 \mathrm{~cm}^{2}$ in females and non-visceral obese (Non-VO) group with VAT below these thresholds.

\section{Statistical analysis}

Results are presented as percentages $(\%)$ and means $( \pm \mathrm{SD})$ or medians and interquartile range (IQR). Normality was assessed using the Kolmogorov-Smirnov test. Chi-square and Fisher exact tests were used for categorical variables while Student t-test or Mann-Whitney U test were used for quantitative variables as appropriate. Relationships between continuous variables were assessed using Spearman rank correlation coefficient analysis and the correlation coefficient $(\rho)$ was calculated.

Univariate analysis was conducted to assess the factors affecting CRP values in the overall population. Subgroup analysis was performed separately for patients who presented infectious complications. The factors analyzed were VO (vs. Non-VO), ERAS (vs. standard care), male gender (vs.female), CCI $>4$ (vs. < 4 ), cancer (vs. benign disease), extent of resection (right hemicolectomyvs. left hemicolectomy vs. rectal resection), need for conversion (vs. no conversion), and surgical time $>$ median (vs. $<$ median). A screened p-value of $<0.10$ at univariate analysis was then considered for entering the multivariate model after validating the absence of multicollinearity. In multivariate logistic regression, a p value $<0.05$ was considered statistically significant.

Since POD3 CRP value is used in our clinical practice as one of the discharge criteria, we tested it as predictor of infectious complications by receiver operating characteristic (ROC) curves analysis. The area under the curve (AUC) is a direct measure of diagnostic accuracy of a test. A test with an AUC between 0.7-0.8 is considered as having a good diagnostic accuracy. Cut-off values with the highest sensitivity and specificity were determined by using the Youden's index. To compare accuracy between ROC curves in subgroup analysis, the DeLong method was applied ${ }^{14}$.

Results were considered statistically significant when $\mathrm{p}$ value was found to be $<0.05$. SPSS software (version 23, SPSS, Inc.) was used for statistical analysis. Graphics were outlined using GraphPad Prism version 9.0.

\section{Results}

Cohort under study

After the selection process, a cohort of 357 patients was included for study purpose. Median (IQR) BMI in the overall population was $25.0(22.9-28.1) \mathrm{kg} / \mathrm{m}^{2}$. Median (IQR) VAT area was $150.4(95.7-212.6) \mathrm{cm}^{2}$ and, as predictable, was higher in males than in females $\left(183.8[125.4-251.7] \mathrm{cm}^{2}\right.$ vs. $103.3[57.5-167.2] \mathrm{cm}^{2}$; p $<0.001)$. After application of sex-specific cut-offs, 222 patients $(62.2 \%)$ were classified as VO and 135 patients $(37.8 \%)$ as non-VO, with no differences in $\mathrm{VO}$ incidence between males and females $(60.3 \%$ vs.64.6\%; $\mathrm{p}=$ $0.41)$.

Baseline clinical and pathological characteristics are shown in Table 1. VO patients were older and had higher BMI $(\mathrm{p}<0.001)$ and CCI $(\mathrm{p}=0.01)$. No relevant differences were found in terms of extent of surgery or staging of malignant disease.

Post-operative outcomes are shown in Table 1. In the overall population, 158 patients (42.3\%) developed post-operative complications, and 30 patients $(8.4 \%)$ suffered a severe complication according to the ClavienDindo classification. No differences were found between the VO and non-VO cohorts, as for overall, major grade and infectious complications. Post-operative LoS was also comparable between groups.

Visceral obesity and SSR

Baseline pre-operative CRP values were significantly associated with VAT both in females $(\rho=0.36, p=0.001)$ and males $(\rho=0.19 ; p=0.04)$. A positive correlation between VAT and post-operative CRP values was found 
both in females and males on POD1 $(\rho=0.24, p=0.001$ and $\rho=0.20, p=0.04)$, POD2 $(\rho=0.32, p<0.001$ and $\rho=0.15, p=0.03)$ and POD3 $(\rho=0.31, p<0.001$ and $\rho=0.17, p=0.02)$, but not on POD4 and POD5.

VO patients displayed higher baseline CRP levels compared to non-VO patients $(3,1-6 \mathrm{mg} / \mathrm{L}$ vs. 1, 1-3 $\mathrm{mg} / \mathrm{L} ; \mathrm{p}<0.001)$. Higher CRP values were also observed in the VO group on POD1, POD2, POD3 and POD5 (Figure 1 and Table 2).

Linear regression analysis showed that VO was positively correlated with CRP from POD 1 to 3, with the highest coefficient on POD2 $(\beta=0.164 ; \mathrm{p}<0.001)$. As showed in Supplementary Table 3, conversion to open surgery and surgical time were positively associated with CRP levels. Conversely, ERAS protocol displayed a negative correlation.

In multivariate analysis (Table 4), VO was confirmed as independent risk factor for increased CRP on POD1 and POD2 but not on POD3 $(\beta=0.062 ; \mathrm{p}=0.23)$. ERAS enrollment was independently associated with reduced CRP values from POD2 to POD5, while conversion to open surgery or duration of surgery were associated with increased CRP values on POD1 and POD1, or with POD 2 and POD3, respectively.

Infectious complications and SSR

No differences in CRP levels according to the presence of $\mathrm{VO}$ were observed in patients with infectious complications (Figure 2b). Univariate analysis in this subgroup of patients did not reveal any association with abnormal CRP values in the post-operative period, so that multivariate analysis was unnecessary (Supplementary Table 1). Further analysis was therefore conducted only for patients without infectious complications. In this subgroup, CRP values were significantly higher in VO compared to non-VO patients on POD1, POD2, POD3 and POD5 (Figure 2a). Univariate analysis showed a positive correlation between CRP from POD 1 to 3, and VO (Supplementary Table 2), with the highest coefficient on POD2 ( $\beta=0.200$; $\mathrm{p}=0.001$ ). In multivariate analysis (Table 5), VO was confirmed as independent risk factor for increased CRP values between POD1-3. Other factors associated with high CRP values were conversion to open surgery (POD1-2) and time of surgery (POD 1-4). ERAS enrollment was independently associated with lower CRP values on POD2, POD3 and POD5.

Assessment of POD3 CRP cut-off values

Considering the outcome of infectious complications, ROC curve analysis revealed an AUC of 0.86 (95\% CI: $0.78-0.95, \mathrm{p}<0.001)$, thus confirming the clinical significance of measuring CRP on POD3, as reliable predictor of infectious complications. In the overall population, the optimal cut-off was $134 \mathrm{mg} / \mathrm{L}$, associated with $80 \%$ sensitivity and $78.9 \%$ specificity. Even considering VO and non-VO separately, CRP value on POD3 was an efficient predictor of infectious complications, displaying an AUC value $>0.85$ (Figure 3). According to the Youden's index, the optimal cut-off value of CRP on POD3 was $136 \mathrm{mg} / \mathrm{dL}(87.5 \%$ sensitivity and $88 \%$ specificity) for non-VO patients, and $154 \mathrm{mg} / \mathrm{dL}$ (83.3\% sensitivity and $81.2 \%$ specificity) for VO patients, respectively.

\section{Discussion}

Body composition assessment in surgical patients has recently gained attention due to the possible clinical implications in developing complications and for long-term survival. For example, low skeletal muscle mass seem to be strongly associated with poor post-operative outcomes especially in cancer patients ${ }^{15-17}$. Reduced skeletal muscle mass may promote the development of a pro-inflammatory environment, basically through onset of insulin resistance, ${ }^{18}$ which is responsible for enhanced SSR after colorectal resection ${ }^{4}$. Similarly, insulin resistance and higher levels of pro-inflammatory cytokines such as IL-6 and TNF- $\alpha$ are associated with abnormal adipose tissue accumulation, in particular excess of visceral adipocytes ${ }^{19}$. Although the chronic systemic inflammation which characterizes $\mathrm{VO}$ is a well-known risk factor for development of several diseases associated with metabolic syndrome ${ }^{19,20}$, the role of VO in worsening surgical outcomes is still debated 19,21,22. Little is known about the role of $\mathrm{VO}$ on acute inflammatory response after colorectal resection. Our study aimed to characterize the magnitude of SSR after laparoscopic colorectal resection according to VO, trying to assess its role in development of infectious complications. We hypothesized that 
VO patients presented higher degree of SSR, thus requiring separate cut-offs for predicting safe discharge on POD3.

Although procalcitonin (PCT) presents higher specificity than CRP in differentiating between inflammation and infection ${ }^{23}$, its use in the clinical practice after colorectal surgery is still limited, and mostly influenced development of severe bacterial infections ${ }^{23-25}$.We therefore chose CRP as an objective marker of SSR, due to its widespread use in clinical practice and its role as predictor of complications ${ }^{2}$. In uncomplicated surgery, CRP is generally low on POD1, then exhibits a maximal increase on POD2 and decreases by POD3. Nonetheless, CRP further increases after POD2 in patients developing adverse events. Consequently, CRP on POD3 is widely considered a reliable marker of severe post-operative adverse events, especially infectious complications. Combined with negative clinical findings, a CRP value below the specific cut-offs on POD3 was found an important marker for allowing safe discharge ${ }^{2}$.

The results of this study confirm our original hypothesis of an association between VO and a proinflammatory environment, as shown by higher baseline and post-operative CRP values in the overall population. Multivariate analysis confirmed VO as an independent risk factor for increased SSR, with higher CRP values on POD1 and 2. Interestingly, the increase in SSR was stronger in patients who did not develop infectious complications. Our results are in line with recent evidence of low SSR due to reduced surgical stress from the synergistic effect of laparoscopy and ERAS protocol ${ }^{1,26}$. Nevertheless, whilst conversion to open surgery and surgical time are well-known factors associated with increased SSR, we demonstrate here for the first time that VO may be responsible for a larger inflammatory response after laparoscopic colorectal resection. However, this association was not confirmed in patients who developed infectious complications. We can speculate that whether VO is associated with higher SSR even in complicated cases, its effect on CRP may be concealed by the greater inflammatory response fostered by infection.

Previous studies evaluating the role of VO on SSR were carried out in patients who underwent minimally invasive esophagectomy. Doyle et al. reported altered patterns of cytokine expression in VO patients both pre- and post-operatively. Despite a heightened immune and inflammatory response, this appeared to have no clinical adverse sequelae for VO subjects ${ }^{27}$.In accordance with these findings, Okamura et al. showed that VAT quartiles were significantly associated with CRP levels both in the overall population and in patients who did not develop post-operative infectious complications ${ }^{28}$. Following the results of these studies, our findings confirm that VO could intensify SSR following laparoscopic colorectal resection, though VO was not responsible for worse post-operative course, since the complication rates appeared to be similar between VO and non-VO patients. Whether increased SSR in VO patients is related to higher magnitude of tissue damage, enhanced inflammatory response, or both these elements would coexist, this cannot be elucidated from the present study.

Infectious complications after colorectal surgery have a major clinical impact as they increase LOS, treatment costs and worsen long-term survival in cancer patients ${ }^{29,30}$. When early diagnosed, they can be treated effectively, and their impact is minimized. In the era of fast-track protocols, several CRP cut-off values have been proposed to ensure safe discharge. Different thresholds has been used depending on surgical procedure and surgical approach, since the amount of normal SSR varies between open ${ }^{31-33}$ and laparoscopic surgery ${ }^{2,34}$. In our opinion, all parameters that could influence SSR should be considered when proposing CRP cut-off values for safe discharge, so that its diagnostic efficiency could be increased. Our study, following previous evidences in minimally invasive esophageal surgery ${ }^{27,28}$, demonstrates increased SSR and CRP production after laparoscopic colorectal resection in patients with increased VAT, both in the overall population and in uncomplicated cases. Consequently, high levels of CRP at POD3 may have different clinical significance in VO and non-VO patients. Notably, avoidance to consider different thresholds for these two groups would decrease the diagnostic performance (i.e., both sensitivity and specificity) of this test. Our analysis with ROC curves demonstrated that the CRP cut-off value at POD3 after minimally invasive colorectal surgery should be differentiated according to patient's body composition, with VO patients presenting higher threshold for safe discharge.

Our study has some limitations, which shall be mentioned. First, the sample size was relatively small since 
we focused on patients undergoing elective surgery with minimally invasive approach. However, this decision allowed us to analyze a more homogeneous population, thus reducing the negative effect of many other confounding factors. Second, this is a retrospective observational study conducted at a single institution. The findings presented in this paper would hence need to be validated in larger and prospective cohorts. Third, since introduction of ERAS protocol, more and more patients have been discharged before POD4, thus reducing the availability of data on CRP values on POD4 and 5.

Our paper also has many strengths. The analysis of CT images and VAT was conducted by a single researcher, with large experience in body composition analysis, who was blinded to post-operative outcomes. Then, as previously mentioned, we selected a homogeneous cohort that limited the differences in clinical, pathological, and surgical variables between the two groups. Moreover, to our knowledge, this is one of the few studies analyzing the impact of VAT and VO on SSR after surgery, and it is the sole to consider patients undergoing minimally invasive colorectal resections.

In conclusion, our findings seemingly confirm the presence of a proinflammatory environment before surgery, highlighting enhanced SSR in VO patients. This increased inflammatory response was significant in the overall population and in patients without infectious complications, whilst our analysis failed to find significant difference in those who developed infectious complications. Interestingly, despite the SSR was increased in VO patients, no differences in post-operative complications could be found. We also confirmed that CRP measured on POD3 may present high sensitivity and specificity in predicting infectious complications, though different cut-off values should be considered for VO and non-VO. Future studies in larger cohorts should hence aim at elucidating the relationship between VAT, increased SSR, and incidence of post-operative complications.

\section{Acknowledgments : none}

Statement of authorship: Conti C., Pedrazzani C., Lippi G., Ruzzenente A., and Guglielmi A., provided study concept and design; Conti C., Turri G., Zamboni G.A., Gecchele G. and Valdegamberi A. collected data; Pedrazzani C., Conti C. Ruzzenente A., Lippi G., and Valdegamberi A. performed data analysis and interpretation; Pedrazzani C., Conti C., and Turri G. drafted the manuscript; Turri G., Gecchele G., Zamboni G.A., Valdegamberi A., Ruzzenente A., Lippi G., and Guglielmi A. provided critical revision of the paper.

All authors read and approved the final version of this manuscript.

\section{References}

1. Mari G, Costanzi A, Crippa J, et al. Surgical stress reduction in elderly patients undergoing elective colorectal laparoscopic surgery within an ERAS protocol. Chir . 2016;111(6):476-480. doi:10.21614/chirurgia.111.6.476

2. Pedrazzani C, Moro M, Mantovani G, et al. C-reactive protein as early predictor of complications after minimally invasive colorectal resection. J Surg Res . 2017;210:261-268. doi:10.1016/j.jss.2016.11.047

3. Watt DG, Horgan PG, McMillan DC. Routine clinical markers of the magnitude of the systemic inflammatory response after elective operation: A systematic review. Surg (United States) . 2015;157(2):362-380. doi:10.1016/j.surg.2014.09.009

4. Reisinger KW, Derikx JPM, van Vugt JLA, et al. Sarcopenia is associated with an increased inflammatory response to surgery in colorectal cancer. Clin Nutr . 2016;35(4):924-927. doi:10.1016/j.clnu.2015.07.005

5. Veenhof AAFA, Vlug MS, Van Der Pas MHGM, et al. Surgical stress response and postoperative immune function after laparoscopy or open surgery with fast track or standard perioperative care: A randomized trial. Ann Surg . 2012;255(2):216-221. doi:10.1097/SLA.0b013e31824336e2

6. Pedrazzani C, Conti C, Mantovani G, et al. Laparoscopic colorectal surgery and Enhanced Recovery after Surgery (ERAS) program: Experience with 200 cases from a single Italian center. Med (United States) . 2018;97(35):4-9. doi:10.1097/MD.0000000000012137 
7. Ling ML, Apisarnthanarak A, Abbas A, et al. APSIC guidelines for the prevention of surgical site infections. Antimicrob Resist Infect Control . 2019;8(1):97-134. doi:10.1186/s13756-019-0638-8

8. Rahbari NN, Weitz J, Hohenberger W, et al. Definition and grading of anastomotic leakage following anterior resection of the rectum: A proposal by the International Study Group of Rectal Cancer.Surgery . 2010;147(3):339-351. doi:10.1016/j.surg.2009.10.012

9. Pedrazzani C, Conti C, Zamboni GA, et al. Impact of visceral obesity and sarcobesity on surgical outcomes and recovery after laparoscopic resection for colorectal cancer. Clin Nutr . 2020;0(0). doi:10.1016/j.clnu.2020.04.004

10. Black D, Mackay C, Ramsay G, et al. Prognostic Value of Computed Tomography: Measured Parameters of Body Composition in Primary Operable Gastrointestinal Cancers. Ann Surg Oncol . 2017;24(8):22412251. doi:10.1245/s10434-017-5829-z

11. Prado CM, Lieffers JR, McCargar LJ, et al. Prevalence and clinical implications of sarcopenic obesity in patients with solid tumours of the respiratory and gastrointestinal tracts: a population-based study.Lancet Oncol . 2008;9(7):629-635. doi:10.1016/S1470-2045(08)70153-0

12. Shen W, Punyanitya M, Wang ZM, et al. Total body skeletal muscle and adipose tissue volumes: Estimation from a single abdominal cross-sectional image. J Appl Physiol . 2004;97(6):2333-2338. doi:10.1152/japplphysiol.00744.2004

13. Doyle SL, Bennett AM, Donohoe CL, et al. Establishing computed tomography-defined visceral fat area thresholds for use in obesity-related cancer research. Nutr Res . 2013;33(3):171-179. doi:10.1016/j.nutres.2012.12.007

14. DeLong ER, DeLong DM, Clarke-Pearson DL. Comparing the Areas under Two or More Correlated Receiver Operating Characteristic Curves: A Nonparametric Approach. Biometrics . 1988;44(3):837. doi:10.2307/2531595

15. Richards $\mathrm{CH}$, Roxburgh CSD, MacMillan MT, et al. The relationships between body composition and the systemic inflammatory response in patients with primary operable colorectal cancer. PLoS One . 2012;7(8). doi:10.1371/journal.pone.0041883

16. McMillan DC. Systemic inflammation, nutritional status and survival in patients with cancer. Curr Opin Clin Nutr Metab Care . 2009;12(3):223-226. doi:10.1097/MCO.0b013e32832a7902

17. Laird BJA, Fallon M, Hjermstad MJ, et al. Quality of life in patients with advanced cancer: Differential association with performance status and systemic inflammatory response. J Clin Oncol . 2016;34(23):27692775. doi:10.1200/JCO.2015.65.7742

18. Mourtzakis M, Prado CMM, Lieffers JR, Reiman T, McCargar LJ, Baracos VE. A practical and precise approach to quantification of body composition in cancer patients using computed tomography images acquired during routine care. Appl Physiol Nutr Metab . 2008;33(5):997-1006. doi:10.1139/H08-075

19. Rickles AS, Iannuzzi JC, Mironov O, et al. Visceral Obesity and Colorectal Cancer: Are We Missing the Boat with BMI? J Gastrointest Surg . 2013;17(1):133-143. doi:10.1007/s11605-012-2045-9

20. Després JP, Lemieux I. Abdominal obesity and metabolic syndrome.Nature . 2006;444(7121):881-887. doi:10.1038/nature05488

21. Martin L, Hopkins J, Malietzis G, et al. Assessment of Computed Tomography (CT)-Defined Muscle and Adipose Tissue Features in Relation to Short-Term Outcomes After Elective Surgery for Colorectal Cancer: A Multicenter Approach. Ann Surg Oncol . 2018;25(9):2669-2680. doi:10.1245/s10434-018-6652-x

22. Malietzis G, Aziz O, Bagnall NM, Johns N, Fearon KC, Jenkins JT. The role of body composition evaluation by computerized tomography in determining colorectal cancer treatment outcomes: A systematic review.Eur J Surg Oncol . 2015;41(2):186-196. doi:10.1016/j.ejso.2014.10.056 
23. Giaccaglia V, Salvi PF, Cunsolo G V., et al. Procalcitonin, as an early biomarker of colorectal anastomotic leak, facilitates enhanced recovery after surgery. J Crit Care . 2014;29(4):528-532. doi:10.1016/j.jcrc.2014.03.036

24. Silvestre J, Rebanda J, Lourenço C, Póvoa P. Diagnostic accuracy of C-reactive protein and procalcitonin in the early detection of infection after elective colorectal surgery - a pilot study. BMC Infect Dis . 2014;14(1):444. doi:10.1186/1471-2334-14-444

25. Lagoutte N, Facy O, Ravoire A, et al. C-reactive protein and procalcitonin for the early detection of anastomotic leakage after elective colorectal surgery: pilot study in 100 patients. J Visc Surg . 2012;149(5):e345e349. doi:10.1016/j.jviscsurg.2012.09.003

26. Wang G, Jiang Z, Zhao K, et al. Immunologic Response After Laparoscopic Colon Cancer Operation Within an Enhanced Recovery Program.J Gastrointest Surg . 2012;16(7):1379-1388. doi:10.1007/s11605-012$1880-\mathrm{z}$

27. Doyle SL, Mongan AM, Donohoe CL, et al. Impact of visceral obesity and metabolic syndrome on the postoperative immune, inflammatory, and endocrine response following surgery for esophageal adenocarcinoma.Dis Esophagus . 2017;30(6):1-11. doi:10.1093/dote/dox008

28. Okamura A, Watanabe M, Fukudome I, et al. Relationship Between Visceral Obesity and Postoperative Inflammatory Response Following Minimally Invasive Esophagectomy. World J Surg . 2018;42(11):3651-3657. doi:10.1007/s00268-018-4675-x

29. Krarup PM, Nordholm-Carstensen A, Jorgensen LN, Harling H. Anastomotic leak increases distant recurrence and long-term mortality after curative resection for colonic cancer: A nationwide cohort study. Ann Surg . 2014;259(5):930-938. doi:10.1097/SLA.0b013e3182a6f2fc

30. Kingham TP, Pachter HL. Colonic Anastomotic Leak: Risk Factors, Diagnosis, and Treatment. J Am Coll Surg . 2009;208(2):269-278. doi:10.1016/j.jamcollsurg.2008.10.015

31. M B, R V, WC H, et al. Survival after laparoscopic surgery versus open surgery for colon cancer: long-term outcome of a randomised clinical trial. Lancet Oncol . 2009;10(1):44-52. doi:10.1016/S1470-2045(08)70310-3

32. Forsmo HM, Pfeffer F, Rasdal A, et al. Compliance with enhanced recovery after surgery criteria and preoperative and postoperative counselling reduces length of hospital stay in colorectal surgery: Results of a randomized controlled trial. Color Dis . 2016;18(6):603-611. doi:10.1111/codi.13253

33. Ortega-Deballon P, Radais F, Facy O, et al. C-reactive protein is an early predictor of septic complications after elective colorectal surgery. World $J$ Surg . 2010;34(4):808-814. doi:10.1007/s00268-009-0367-x

34. Singh PP, Zeng ISL, Srinivasa S, Lemanu DP, Connolly AB, Hill AG. Systematic review and metaanalysis of use of serum C-reactive protein levels to predict anastomotic leak after colorectal surgery. $\mathrm{Br} J$ Surg . 2014;101(4):339-346. doi:10.1002/bjs.9354

\section{TABLES}

Table 1. Clinic and pathological characteristics in the VO and Non-VO groups

\begin{tabular}{llllll}
\hline Parameter & Parameter & Parameter & VO $\mathbf{n}=\mathbf{2 2 2}$ & $\begin{array}{l}\text { Non-VO } \mathbf{n}= \\
\mathbf{1 3 5}\end{array}$ \\
& & & & $\mathbf{p}$ & \\
Gender, male & Gender, male & Gender, male & $120(54.1)$ & $79(58.5)$ & 0.41 \\
Age, years & Age, years & Age, years & $68.9+11.3$ & $63.3+12.7$ & $<0.001$ \\
BMI, $\mathrm{kg} / \mathrm{m}^{2}$ & BMI, $\mathrm{kg} / \mathrm{m}^{2}$ & BMI, $\mathrm{kg} / \mathrm{m}^{2}$ & 26.5 & 23.6 & $<0.001$ \\
ERAS & ERAS & ERAS & $(24.2-29.4)$ & $(21.6-24.8)$ & \\
& & & $150(67.6)$ & $99(73.3)$ & 0.25
\end{tabular}




\begin{tabular}{|c|c|c|c|c|c|}
\hline $\begin{array}{l}\text { Charlson's } \\
\text { comorbidity } \\
\text { index }\end{array}$ & $\begin{array}{l}\text { Charlson's } \\
\text { comorbidity } \\
\text { index }\end{array}$ & $\begin{array}{l}\text { Charlson's } \\
\text { comorbidity } \\
\text { index }\end{array}$ & $4(3-5)$ & $3(2-5)$ & 0.01 \\
\hline \multirow{6}{*}{$\begin{array}{l}\text { Surgical } \\
\text { indication }\end{array}$} & Surgical & Surgical & & & 0.93 \\
\hline & indication & indication & & & \\
\hline & Colon cancer & Colon cancer & $116(52.3)$ & $72(53.3)$ & \\
\hline & Rectal cancer & Rectal cancer & $54(24.3)$ & $29(21.5)$ & \\
\hline & Adenoma & Adenoma & $18(8.1)$ & $11(8.1)$ & \\
\hline & $\begin{array}{l}\text { Diverticular } \\
\text { disease }\end{array}$ & $\begin{array}{l}\text { Diverticular } \\
\text { disease }\end{array}$ & $34(15.3)$ & $23(17)$ & \\
\hline $\begin{array}{l}\text { Neoadjuvant } \\
\text { therapy* }\end{array}$ & $\begin{array}{l}\text { Neoadjuvant } \\
\text { therapy* }\end{array}$ & $\begin{array}{l}\text { Neoadjuvant } \\
\text { therapy* }\end{array}$ & $25(14.7)$ & $13(12.9)$ & 0.67 \\
\hline \multirow[t]{3}{*}{ TNM stage* } & TNM stage* & TNM stage* & & & 0.17 \\
\hline & $\begin{array}{l}\text { TNM stage I / } \\
\text { II }\end{array}$ & $\begin{array}{l}\text { TNM stage I / } \\
\text { II }\end{array}$ & $111(65.3)$ & $57(56.4)$ & \\
\hline & $\begin{array}{l}\text { TNM stage III } \\
\text { / IV }\end{array}$ & $\begin{array}{l}\text { TNM stage III } \\
\text { / IV }\end{array}$ & $59(34.7)$ & $44(43.6)$ & \\
\hline \multirow[t]{4}{*}{$\begin{array}{l}\text { Surgical } \\
\text { procedure }\end{array}$} & $\begin{array}{l}\text { Surgical } \\
\text { procedure }\end{array}$ & $\begin{array}{l}\text { Surgical } \\
\text { procedure }\end{array}$ & & & 0.84 \\
\hline & $\begin{array}{l}\text { Right } \\
\text { hemicolectomy }\end{array}$ & $\begin{array}{l}\text { Right } \\
\text { hemicolectomy }\end{array}$ & $73(32.9)$ & $43(31.9)$ & \\
\hline & $\begin{array}{l}\text { Left } \\
\text { hemicolectomy }\end{array}$ & $\begin{array}{l}\text { Left } \\
\text { hemicolectomy }\end{array}$ & $79(35.6)$ & $51(37.8)$ & \\
\hline & $\begin{array}{l}\text { Rectal } \\
\text { resection }\end{array}$ & $\begin{array}{l}\text { Rectal } \\
\text { resection }\end{array}$ & $70(31.6)$ & $41(30.4)$ & \\
\hline $\begin{array}{l}\text { Associated } \\
\text { resections }\end{array}$ & $\begin{array}{l}\text { Associated } \\
\text { resections }\end{array}$ & $\begin{array}{l}\text { Associated } \\
\text { resections }\end{array}$ & $47(21.2)$ & $23(17)$ & 0.34 \\
\hline $\begin{array}{l}\text { Surgical time, } \\
\text { min }\end{array}$ & $\begin{array}{l}\text { Surgical time, } \\
\text { min }\end{array}$ & $\begin{array}{l}\text { Surgical time, } \\
\text { min }\end{array}$ & 237 (190-297) & $220(191-270)$ & 0.18 \\
\hline Blood loss, ml & Blood loss, ml & Blood loss, ml & $50(30-100)$ & $40(30-90)$ & 0.16 \\
\hline Conversion & Conversion & Conversion & $18(8.1)$ & $6(4.4)$ & 0.18 \\
\hline \multirow[t]{3}{*}{$\begin{array}{l}\text { Overall } \\
\text { complications }\end{array}$} & $\begin{array}{l}\text { Overall } \\
\text { complications }\end{array}$ & $\begin{array}{l}\text { Overall } \\
\text { complications }\end{array}$ & $94(42.3)$ & $57(42.2)$ & 0.98 \\
\hline & & Minor grade & $77(34.7)$ & $44(32.6)$ & 0.78 \\
\hline & & Major grade & $17(7.7)$ & $13(9.6)$ & 0.52 \\
\hline \multirow[t]{4}{*}{$\begin{array}{l}\text { Infectious } \\
\text { complications }\end{array}$} & $\begin{array}{l}\text { Infectious } \\
\text { complications }\end{array}$ & $\begin{array}{l}\text { Infectious } \\
\text { complications }\end{array}$ & $34(15.3)$ & $23(17)$ & 0.67 \\
\hline & & Pneumonia & $8(3.6)$ & $7(5.2)$ & 0.47 \\
\hline & & $\begin{array}{l}\text { Anastomotic } \\
\text { leak }\end{array}$ & $12(5.4)$ & $8(5.9)$ & 0.84 \\
\hline & & $\begin{array}{l}\text { Surgical site } \\
\text { infections }\end{array}$ & $11(5)$ & $7(5.2)$ & 0.92 \\
\hline $\begin{array}{l}\text { Time to } \\
\text { infectious } \\
\text { complication, } \\
\text { days }\end{array}$ & $\begin{array}{l}\text { Time to } \\
\text { infectious } \\
\text { complication, } \\
\text { days }\end{array}$ & $\begin{array}{l}\text { Time to } \\
\text { infectious } \\
\text { complication, } \\
\text { days }\end{array}$ & $4(2-5.25)$ & $4(3-7)$ & 0.44 \\
\hline Mortality & Mortality & Mortality & $1(0.5)$ & $1(0.7)$ & 0.72 \\
\hline Readmission & Readmission & Readmission & $7(3.2)$ & $5(3.7)$ & 0.78 \\
\hline Redo surgery & Redo surgery & Redo surgery & $10(4.5)$ & $9(6.7)$ & 0.38 \\
\hline $\begin{array}{l}\text { Length of stay, } \\
\text { days }\end{array}$ & $\begin{array}{l}\text { Length of stay, } \\
\text { days }\end{array}$ & $\begin{array}{l}\text { Length of stay, } \\
\text { days }\end{array}$ & $6(5-8)$ & $6(4-8)$ & 0.30 \\
\hline
\end{tabular}


* Percentage on 271 colon and rectal cancers.

Table 2. Surgical stress response expressed as CRP values in the overall population and according to visceral obesity

\begin{tabular}{lllll}
\hline Parameter & $\begin{array}{l}\text { Overall } \\
\text { population } \mathbf{n}=\end{array}$ & Visceral obesity & Visceral obesity & Visceral obesity \\
& $\mathbf{3 5 7}$ & VO $\mathbf{n}=\mathbf{2 2 2}$ & $\begin{array}{l}\text { Non-VO } \mathbf{~}=\mathbf{1 2 5} \\
1(1-3)\end{array}$ & $\mathbf{p}$ \\
Pre-operative & $2(1-5)$ & $3(1-6)$ & & $<0.001$ \\
CRP & & $65(45-99)$ & $54(40-81)$ & 0.002 \\
CRP POD1 & $62(43-95)$ & $112(71-169)$ & $88(53-138)$ & 0.001 \\
CRP POD2 & $102(61-156)$ & $92(52-143)$ & $71(34-111)$ & 0.003 \\
CRP POD3 & $85(45-132)$ & $83(36-150)$ & $73(36-117)$ & 0.50 \\
CRP POD4 & $74(36-135)$ & $57(26-113)$ & $44(19-79)$ & 0.04 \\
CRP POD5 & $52(23-103)$ & & & \\
\hline
\end{tabular}

POD: post-operative day

Table 3. Univariate analysis for factors affecting CRP values

\begin{tabular}{lllllllll}
\hline Factor & Crp POD1 & Crp POD1 & Crp POD2 & Crp POD2 & Crp POD3 & Crp POD3 & Crp POD4 & Crp POD \\
& $\beta$ & $\mathrm{P}$ & $\beta$ & $\mathrm{p}$ & $\beta$ & $\mathrm{p}$ & $\beta$ & $\mathrm{p}$ \\
VO & 0.151 & 0.004 & 0.164 & 0.003 & 0.125 & 0.02 & 0.029 & 0.74 \\
ERAS & -0.151 & 0.004 & -0.292 & $<0.001$ & -0.332 & $<0.001$ & -0.281 & 0.001 \\
Male gender & 0.047 & 0.38 & 0.081 & 0.14 & 0.043 & 0.39 & 0.074 & 0.39 \\
CCI & 0.075 & 0.16 & 0.136 & 0.01 & 0.154 & 0.004 & 0.017 & 0.84 \\
Cancer & 0.089 & 0.09 & 0.128 & 0.02 & 0.126 & 0.02 & 0.011 & 0.90 \\
Specimen length & -0.006 & 0.91 & 0.034 & 0.53 & 0.103 & 0.05 & 0.137 & 0.11 \\
Conversion & 0.170 & 0.001 & 0.143 & 0.01 & 0.085 & 0.11 & 0.098 & 0.25 \\
Surgical time & 0.208 & $<0.001$ & 0.261 & $<0.001$ & 0.245 & $<0.001$ & 0.176 & 0.04 \\
\hline
\end{tabular}

VO: visceral obesity; CCI: Charlson's comorbidity index

Table 4. Multivariate analysis for factors affecting CRP values in the overall population

\begin{tabular}{lllllllll}
\hline Factor & Crp POD1 & Crp POD1 & Crp POD2 & Crp POD2 & Crp POD3 & Crp POD3 & Crp POD4 & Crp POD \\
& $\beta$ & $\mathrm{p}$ & $\beta$ & $\mathrm{p}$ & $\beta$ & $\mathrm{p}$ & $\beta$ & $\mathrm{p}$ \\
VO & 0.119 & 0.02 & 0.121 & 0.02 & - & - & & \\
ERAS & - & - & -0.144 & 0.01 & -0.279 & $<0.001$ & -0.255 & 0.004 \\
Male gender & & & & & & & & \\
CCI & & - & - & - & - & - & \\
Cancer & - & - & - & - & - & - & \\
Specimen length & & & & & - & - & & \\
Conversion & 0.146 & 0.01 & - & - & & & \\
Surgical time & 0.137 & 0.01 & 0.177 & 0.01 & 0.193 & $<0.001$ & - & \\
\hline
\end{tabular}

VO: visceral obesity; CCI: Charlson's comorbidity index

Table 5. Multivariate analysis for factors affecting CRP values in patients without infectious complications 


\begin{tabular}{lllllllll}
\hline Factor & Crp POD1 & Crp POD1 & Crp POD2 & Crp POD2 & Crp POD3 & Crp POD3 & Crp POD4 & Crp POD \\
& $\beta$ & $\mathrm{p}$ & $\beta$ & $\mathrm{P}$ & $\beta$ & $\mathrm{p}$ & $\beta$ & $\mathrm{p}$ \\
VO & 0.141 & 0.01 & 0.156 & 0.01 & 0.124 & 0.03 & & \\
ERAS & - & - & -0.165 & 0.01 & -0.199 & 0.001 & - & \\
Male gender & & & & & & & & - \\
CCI & & & - & - & - & - & & \\
Cancer & & & - & - & - & - & & - \\
Specimen length & & & & & & & & \\
Conversion & 0.218 & $<0.001$ & 0.163 & 0.004 & - & - & - & 0.01 \\
Surgical time & 0.195 & 0.001 & 0.251 & $<0.001$ & 0.267 & $<0.001$ & 0.289 & \\
\hline
\end{tabular}

VO: visceral obesity; CCI: Charlson's comorbidity index

Supplementary Table 1. Univariate analysis for factors affecting CRP values in patients with infectious complications

\begin{tabular}{lllllllll}
\hline Factor & Crp POD1 & Crp POD1 & Crp POD2 & Crp POD2 & Crp POD3 & Crp POD3 & Crp POD4 & Crp POD \\
& $\beta$ & $\mathrm{p}$ & $\beta$ & $\mathrm{p}$ & $\beta$ & $\mathrm{p}$ & $\beta$ & $\mathrm{p}$ \\
VO & 0.113 & 0.40 & 0.113 & 0.42 & 0.092 & 0.50 & 0.146 & 0.45 \\
ERAS & 0.041 & 0.76 & -0.038 & 0.79 & -0.259 & 0.05 & -0.211 & 0.27 \\
Male gender & 0.197 & 0.14 & 0.294 & 0.03 & 0.301 & 0.02 & 0.326 & 0.10 \\
CCI & 0.021 & 0.88 & -0.027 & 0.85 & -0.005 & 0.97 & -0.117 & 0.55 \\
Cancer & 0.148 & 0.27 & 0.082 & 0.59 & 0.159 & 0.24 & 0.113 & 0.56 \\
Specimen length & -0.085 & 0.53 & -0.132 & 0.35 & 0.026 & 0.85 & -0.005 & 0.98 \\
Conversion & -0.075 & 0.58 & -0.230 & 0.10 & -0.200 & 0.14 & -0.081 & 0.68 \\
Surgical time & 0.028 & 0.85 & -0.052 & 0.72 & -0.052 & 0.72 & -0.142 & 0.47 \\
\hline
\end{tabular}

VO: visceral obesity; CCI: Charlson's comorbidity index

Supplementary Table 2. Univariate analysis for factors affecting CRP values in patients without infectious complications

\begin{tabular}{lllllllll}
\hline Factor & Crp POD1 & Crp POD1 & Crp POD2 & Crp POD2 & Crp POD3 & Crp POD3 & Crp POD4 & Crp POD \\
& $\beta$ & $\mathrm{p}$ & $\beta$ & $\mathrm{P}$ & $\beta$ & $\mathrm{p}$ & $\beta$ & $\mathrm{p}$ \\
VO & 0.168 & 0.003 & 0.200 & 0.001 & 0.173 & 0.003 & 0.081 & 0.40 \\
ERAS & -0.144 & 0.01 & -0.293 & $<0.001$ & -0.296 & $<0.001$ & -0.197 & 0.04 \\
Male gender & 0.018 & 0.75 & 0.040 & 0.50 & 0.060 & 0.31 & -0.029 & 0.77 \\
CCI & 0.055 & 0.34 & 0.139 & 0.02 & 0.168 & 0.004 & 0.065 & 0.51 \\
Cancer & 0.082 & 0.16 & 0.153 & 0.01 & 0.138 & 0.02 & 0.040 & 0.68 \\
Specimen length & -0.014 & 0.80 & 0.035 & 0.56 & 0.097 & 0.10 & 0.095 & 0.33 \\
Conversion & 0.220 & $<0.001$ & 0.250 & $<0.001$ & 0.196 & 0.001 & 0.185 & 0.05 \\
Surgical time & 0.220 & $<0.001$ & 0.321 & $<0.001$ & 0.334 & $<0.001$ & 0.329 & 0.001 \\
\hline
\end{tabular}

VO: visceral obesity; CCI: Charlson's comorbidity index

\section{FIGURE LEGENDS}

Figure 1 : trend in post-operative CRP in the overall population according to VO status $\left({ }^{*} \mathrm{p}<0.05\right)$

Figure 2 : trend in post-operative CRP values in a) patients without infectious complications and b) 
patients with post-operative infectious complications according to VO status $\left({ }^{*} \mathrm{p}<0.05\right)$

Figure 3 : ROC curves for CRP levels on POD3 show good sensitivity and specificity for detection of infectious complications both in VO and Non-VO patients
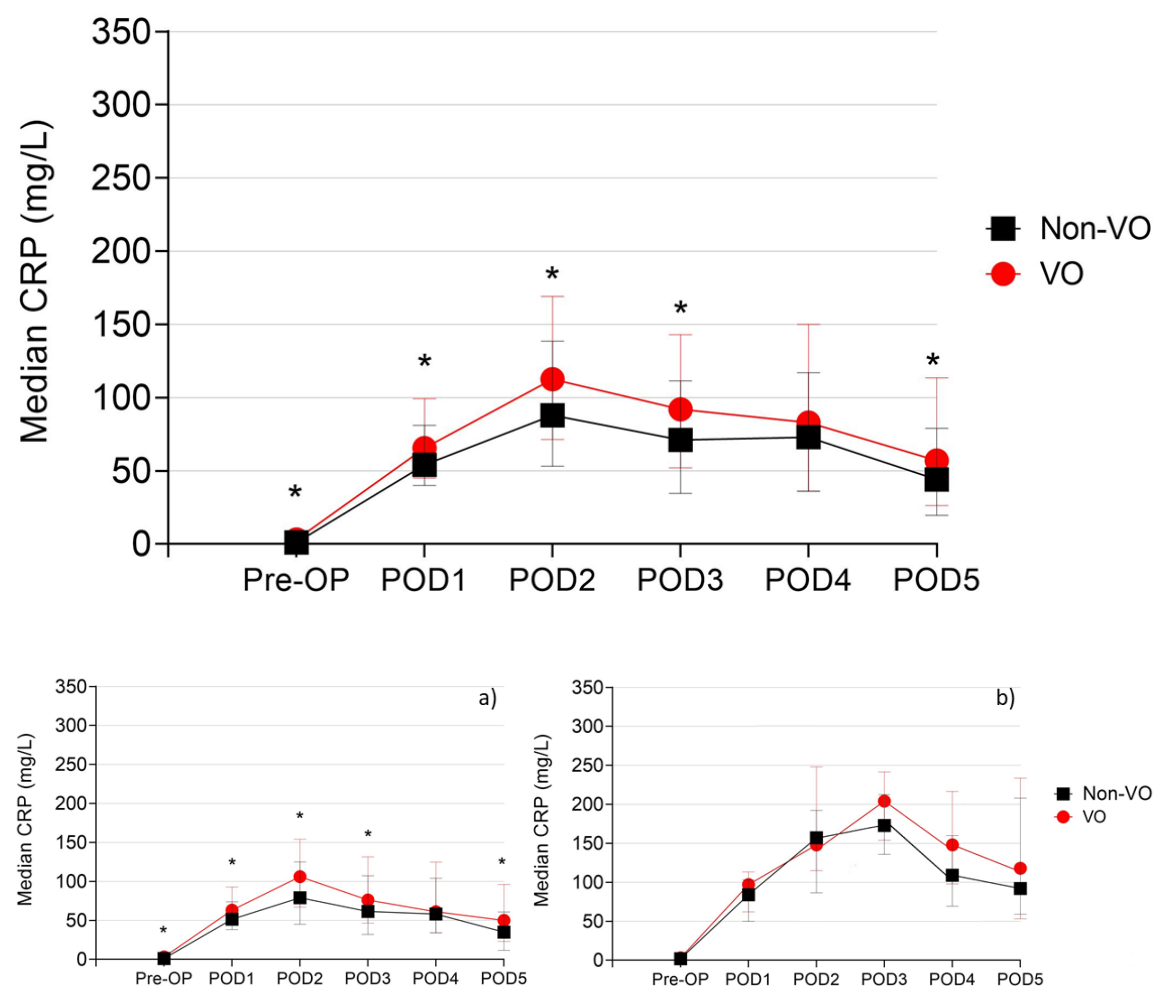


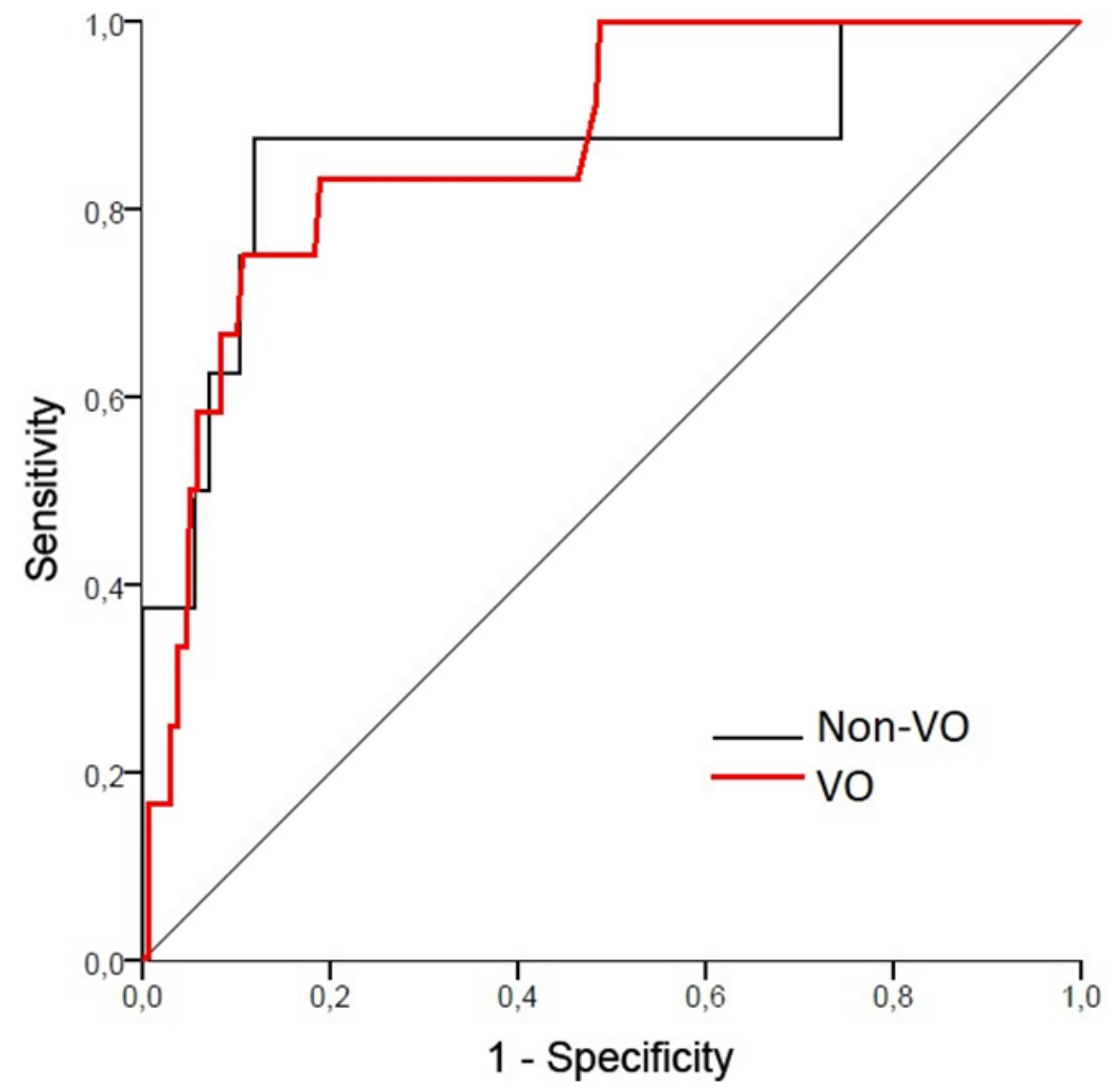

\section{Hosted file}

CRPfat_Table 1.docx available at https://authorea.com/users/424587/articles/529650-visceralobesity-enhances-inflammatory-response-after-laparoscopic-colorectal-resection

\section{Hosted file}

CRPfat_Table 2.docx available at https://authorea.com/users/424587/articles/529650-visceralobesity-enhances-inflammatory-response-after-laparoscopic-colorectal-resection

\section{Hosted file}

CRPfat_Table 3.docx available at https://authorea.com/users/424587/articles/529650-visceralobesity-enhances-inflammatory-response-after-laparoscopic-colorectal-resection

\section{Hosted file}

CRPfat_Table 4.docx available at https://authorea.com/users/424587/articles/529650-visceralobesity-enhances-inflammatory-response-after-laparoscopic-colorectal-resection

\section{Hosted file}

CRPfat_Table 5.docx available at https://authorea.com/users/424587/articles/529650-visceralobesity-enhances-inflammatory-response-after-laparoscopic-colorectal-resection 